\title{
Clinical features of the patient with multiple primary tumors: Single center experience
}

\author{
Ali Gokyer, ${ }^{1}$ Osman Kostek, ${ }^{2}$ Muhammet Bekir Hacioglu, ${ }^{2}$ Bulent Erdogan, ${ }^{2}$ Hilmi Kodaz, ${ }^{2}$ \\ Esma Turkmen, ${ }^{2}$ Ilhan Hacibekiroglu, ${ }^{2}$ Sernaz Uzunoglu, ${ }^{2}$ Irfan Cicin ${ }^{2}$ \\ ${ }^{1}$ Department of Internal Medicine, Trakya University Faculty of Medicine, Edirne, Turkey \\ ${ }^{2}$ Division of Medical Oncology, Department of Internal Medicine, Trakya University, Balkan Oncology Hospital, Edirne, Turkey
}

\begin{abstract}
OBJECTIVE: Multiple primary tumors are the ones that develop in the same patient at the same or different times. They are usually examined under two groups. If the second tumor is diagnosed 6 months after the first tumor is diagnosed, it is named as metachronous tumor. If it is diagnosed in 6 months after the first diagnosis, it is called as synchronous tumor. The malignancy of tumors should be proved histologically. At least $2 \mathrm{~cm}$ of solid tissue should be present between two tumors. If they are at localized at the same place, a gap of at least 5 years should be present between them. Metastatic disease should be eliminated.This study aimedto review the clinical, demographic, and pathological features of multiple primary tumors, detect the prevalence, compare the results with literature findings, and evaluate and improve the approach to multiple primary tumors.
\end{abstract}

METHODS: A total of 170 patients diagnosed with multiple primary tumors were included in this study. Patient data were obtained from pathology and medical reports of the patients.

RESULTS: Most of the multiple primary tumors were metachronous. The number of male patients was more than that of female patients. The median time between double tumors was 3 monthsforsynchronous tumorsand 26 months for metachronous tumors. Synchronous tumors with the highest prevalence of comorbidity were lung-larynx and lung-colon, whereas metachronous tumors with the highest prevalence of comorbidity were lung-bladder, lung-larynx, breast-endometrium, and breast-colon. The history of smoking and alcohol was found to be higher in male patients andsynchronous tumors.

CONCLUSION: The detection of the first tumor in the metastatic stage and an accompanying synchronous secondary tumor was found to be a poor prognostic factor. The treatment of the first tumor, smoking, squamous cell histology, and male gender were among the other factors negatively affecting survival,although they were not statistically significant.

Keywords: Metachronous; multiple primary tumors; survival; synchronous. 
6 months after the first tumor is diagnosed, it is named as metachronous tumor, whereas if it is diagnosed in 6 months after the first diagnosis, it is called as synchronous tumor [3]. The formation of the second tumor occurs as a result of a series of complex interactions. The first tumor increases the risk of developing secondary tumor [4]. Also, smoking, alcohol intake, environmental factors, and genetic mutations increase the risk of developing secondary tumor. The chances of developing secondary tumorsare increased by additive and synergistic effect of the treatment with combined chemotherapy and radiotherapy applications. All patients should undergo special surveillance and should be followedup and treated with methods such as prophylactic surgery if necessary.

This studyaimed to evaluate the clinical, demographic, and pathological features of multiple primary tumors, and compare the results with literature findings. The findings might contribute to future approaches to multiple primary tumors.

\section{MATERIALS AND METHODS}

\section{Patient features}

This was a retrospective descriptive case series study, and all the cases with cancer diagnosis in the Trakya University medical oncology department between 2005 and 2015 were evaluated retrospectively. The medical recordsof 10,000 patients were analyzed before the study. The medical records of 180 patients with multiple primary tumors were included in the study. The patients with basal cell skin carcinoma as one of the tumors, out of 10 patients with multiple primary tumors, were excluded from the study (Figure 1).

\section{Study design}

The age and sex of the patients, history of smoking and alcohol use, age of first tumor diagnosis, first tumor organ, first tumor histology, first tumor site, first tumor stage, first tumor treatment, second tumor age, second tumor organ, second tumor histology, second tumor site, second tumor stage, second tumor treatment, synchronous and metachronous

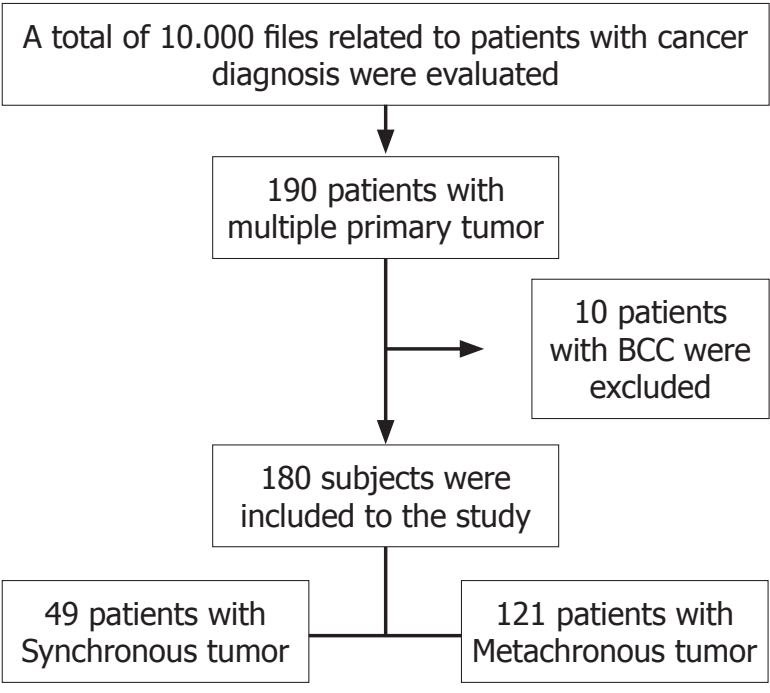

FIGURE 1. Method of selection of patient group.

coexistence of double tumors and their fates, diagnosis date of the tumors, and difference between their diagnosis dates in months was recorded. Tumor stage was considered as metastatic disease and organ-limited disease. The smoking history of the patient was identified as having a cigarette story or not smoking. The tissue diagnoses in pathology reports were noted. Tumor treatment options were obtained from follow-up and treatment files. Treatment options were also categorized as curative and noncurative. If the secondtumor is diagnosed 6 months after the first tumor is diagnosed, it is named as metachronous tumor, whereas if it is diagnosed in 6 months after the first diagnosis, it is called as synchronous tumor. Also, each tumor with tissue biopsies was shown to be malignant with clinical and histological features, indicating that these tumors did not occur due to recurrence or metastasis of other tumors. The cases without tissue diagnosis or the ones with tissue diagnosis whose tumor could not be shown as malignant with immunohistological and/or histopathological staining were not included in this study. The fate of the patients was given as dead or being followedup. The present age of the patients who were being followedup was determined. The age on the death date and the death date were also determined for the dead patients. Based on the pathology reports, the 
exact diagnosis dates of the first and second tumors were recorded. The time between these two dates was recorded in months.Medical oncology records, hospital files, automation system, and pathology laboratory records were used during data collection. The information on the recent status of the patients who had at least 6 months over their last followup was provided by phone. The death records were obtained from the Ministry of Health death notification system. The date of diagnosis was taken as the time of the pathologic diagnosis or the time of surgery in patients without preoperative diagnosis.

\section{Statistical analysis}

Univariate and multivariate analyses were performed. Mean and median values of the patients were determined by descriptive statistics. Standard deviation $( \pm)$ was used. The parametric variables were compared between groups using theindependent-samplet test. Nonparametric variables were evaluated using the chi-square test. Kaplan-Meier method was used for survival analyses. The confidence interval was considered as $95 \%$, and a p value less than 0.05 was considered as statisticallysignificant. All data were entered in SPSS 20.0 for Windows (SPSS; Chicago, IL, USA).

\section{RESULTS}

\section{Study group features}

The prevalence of multiple primary tumors was $1.9 \%$ in all patients. The patients were basically divided into two groups: ones with synchronous and metachronous tumors. Further, 49 patients (28\%) hadsynchronous tumors and 121 patients (72\%) hadmetachronous tumors (Figure 1).

The clinical and demographic data of the patients areshown in Table 1 . The rate of smoking was significantly higher in patients with synchronous tumorsthan in patients with metachronous tumors. Similarly, the rates of metastatic disease were higherin patients with synchronous tumors than in patients with metachronous tumors (Table 1).

The prevalence order of the origin of primary tumor in the patients with synchronous tumorswas colon (10), lung (9), larynx (6), prostate (4), skin (4), breast (3), bladder (3), endometrium (3), pancreas (2), stomach (2), thyroid (1), ovary (1), esophagus (1). Thirty-three $(67.3 \%)$ of these tumors had adenocarcinoma histology, 14 (28.6\%) had squamous cell carcinoma histology, 1had follicular carcinoma, and 1 had melanoma histology. Twenty-one patients (42.9\%) had metastatic disease, and 28 patients (57.1\%) had organ-limited disease.

The prevalence order of the origin of secondary tumorin the patients with synchronous tumor waslungs (15), colon (10), kidney (5), bladder (4), prostate (3), ovary(3), larynx (3), pancreas (2), endometrium (1), and stomach (1). Thirty-eight of these tumors (76.6\%) had adenocarcinoma histology, and 11 tumors (22.4\%) had squamous cell carcinoma histology. Twenty-two patients $(44.9 \%)$ had metastatic disease, whereas 27 patients $(55.1 \%)$ had organ-limited disease.

Twenty-nine $(59.2 \%)$ of the patients with synchronous tumor died, and 20 patients $(40.8 \%)$ carried on with their clinical follow-ups. When the co-occurrence of double tumors was analyzed in months, the mean was $2.63 \pm 1.56$ (median 3; range 0-6). Co-occurrence was most frequently detected in five patients with colon-lung and fivepatients with lung-laryngeal (Table 2).

One hundred and twenty-one patients with metachronous tumors were detected. Fortynine of these patients were female $(40.5 \%)$ and 72 male $(59.5 \%)$. The mean age of the patients was $62 \pm 12.13$ years (median 63 years; range 36-89 years). Thirty patients (24.8\%)drank alcohol, and 91 patients $(75.2 \%)$ did not drink alcohol. Of the patients, $61(50.4 \%)$ had smoking history and 60 $(49.6 \%)$ of them did notsmoke.

The mean age of primary tumor in patients with metachronous tumors was $56 \pm 13.00$ (median 57, range 20-88). According to the prevalence order of the tumor source, tumorswere detected in the breast (25), colon (16), larynx (16), bladder (12), prostate (9), skin (8), endometrium (8), lungs (7), kidney (6), ovary (5), testis (2), stomach (2), thyroid (1), nose (1), esophagus (1), liver (1), and cervix (1). Of these tumors, 89 had adenocarcinoma histology 
TABLE 1. Clinical and demographic characteristics of subjects

\begin{tabular}{|c|c|c|c|c|}
\hline & \multicolumn{2}{|c|}{$\begin{array}{l}\text { Synchronous tumour } \\
\qquad(n=49)\end{array}$} & \multicolumn{2}{|c|}{$\begin{array}{l}\text { Metachronous tumour } \\
\qquad(\mathrm{n}=121)\end{array}$} \\
\hline & $\mathrm{n}$ & $\%$ & $\mathrm{n}$ & $\%$ \\
\hline Age, year & \multicolumn{2}{|c|}{$64 \pm 12$} & \multicolumn{2}{|c|}{$62 \pm 12$} \\
\hline Gender, M/F & \multicolumn{2}{|c|}{$11 / 38$} & \multicolumn{2}{|c|}{$49 / 72$} \\
\hline Smoking* & 33 & 67.3 & 61 & 50.4 \\
\hline Alcoholconsumption & 13 & 26.5 & 30 & 24.8 \\
\hline \multicolumn{5}{|l|}{ Histopathology of primarytumour, } \\
\hline Adenocancer & 33 & 67.3 & 89 & 73.5 \\
\hline Squamouscellcancer & 14 & 28.6 & 29 & 24.0 \\
\hline Others** & 2 & 4.1 & 3 & 2.5 \\
\hline \multicolumn{5}{|l|}{ Stage of primarytumour** } \\
\hline Localized & 28 & 57.1 & 97 & 80.2 \\
\hline Metastatic & 21 & 42.9 & 24 & 19.8 \\
\hline \multicolumn{5}{|l|}{ Histopathology of secondarytumour } \\
\hline Adenocancer & 38 & 76.6 & 94 & 77.6 \\
\hline Squamouscellcancer & 11 & 22.4 & 26 & 21.4 \\
\hline \multicolumn{5}{|l|}{ Stage of secondarytumour } \\
\hline Localized & 27 & 55.1 & 69 & 57.1 \\
\hline Metastatic & 21 & 44.9 & 52 & 42.9 \\
\hline \multicolumn{5}{|c|}{ Time intervalbetweensecondtumour (month)** } \\
\hline Median (Interquartile range) & \multicolumn{2}{|c|}{$3(1-4)$} & \multicolumn{2}{|c|}{$26(13-68)$} \\
\hline Minimum- maximum & \multicolumn{2}{|c|}{$0-6$} & \multicolumn{2}{|c|}{$7-312$} \\
\hline \multicolumn{5}{|l|}{ Clinicaloutcome } \\
\hline Death & 29 & 59.2 & 61 & 50.4 \\
\hline
\end{tabular}

(73\%), 29 had squamous cell carcinoma histology (24\%), 2 had seminoma histology (1.7\%) and 1 had follicular cancer histology. Twenty-four patients $(19.8 \%)$ had metastatic disease, whereas 97 patients $(80.2 \%)$ had an organ-limited disease.

The mean age of the secondary tumor in patients with metachronous tumors was $60 \pm 12.8$ years (median 61; range 34-89). The tumors were classified according to the prevalence orderas lung (35), colon (21), breast (9), bladder (8), endometrium (8), prostate (7), kidney (6), larynx (6), pancreas (3), skin (3), stomach (2), tongue (2), thyroid (2), esophagus (1), biliary tract (1), and ureter (1) (Table 2). Ninety-four of these tumors had adeno- carcinoma histology (77.7\%), 26 had squamous cell carcinoma histology (21.5\%), and 1 had follicular cancer histology. Sixty-nine patients (57\%) had metastatic disease, and 52 patients (43\%) had an organ-limited disease.

Of patients with a metachronous disease, 61 patients (50.4\%) died and 60 patients (49.6\%) continued with their treatment in the outpatient clinic. The mean age of the co-occurrence of double tumors in months was $50 \pm 60.26$ months (median 26months; range 7-312 months). In terms of tumor co-occurrence, 10 patients with lung-bladder, 10 patients with larynx-lung, 9 patients with breast-endometrium, 8 patients with breast-co- 
TABLE2. Tumours location in patients with multiple primary tumours related to their organ involvement

\begin{tabular}{|c|c|c|c|c|c|}
\hline & $\begin{array}{l}\text { Synchronous } \\
\text { tumour }(n=49)\end{array}$ & $\begin{array}{l}\text { Metachronous } \\
\text { tumour }(n=49)\end{array}$ & & $\begin{array}{l}\text { Synchronous } \\
\text { tumour }(n=49)\end{array}$ & $\begin{array}{l}\text { Metachronous } \\
\text { tumour }(n=49)\end{array}$ \\
\hline Colon, $\mathrm{n}$ (count) & & & Larynx & - & 1 \\
\hline Lung & 5 & 4 & Stomach, $\mathrm{n}$ (count) & & \\
\hline Kidney & 3 & 1 & Pancreas & 1 & - \\
\hline Endometrium & 3 & 2 & Prostat & 1 & - \\
\hline Colon & 2 & - & Endometrium & - & 1 \\
\hline Prostat & 2 & - & Tongue & - & 1 \\
\hline Bladder & 1 & 3 & Kidney, n (count) & & \\
\hline Skin & 1 & 1 & Thyroid & 1 & - \\
\hline Larynx & 1 & - & Lung & - & 3 \\
\hline Ovary & - & 2 & Colon & - & 1 \\
\hline Stomach & - & 1 & Skin & - & 1 \\
\hline Lung, $\mathrm{n}$ (count) & & & Bladder & - & 1 \\
\hline Larynx & 5 & - & Breast, $n$ (count) & & \\
\hline Pancreas & 3 & - & Colon & - & 7 \\
\hline Skin & 3 & - & Endometrium & - & 5 \\
\hline Bladder & 2 & 4 & Ovary & - & 4 \\
\hline Kidney & 1 & 2 & Breast & - & 3 \\
\hline Stomach & 1 & - & Kidney & - & 2 \\
\hline Breast & 1 & - & Thyroid & - & 2 \\
\hline Prostat & 1 & 1 & Lung & - & 2 \\
\hline Ovary & 1 & - & Endometrium, $\mathrm{n}$ (count) & & \\
\hline Larynx, n (count) & & & Breast & - & 4 \\
\hline Lung & - & 9 & Lung & - & 3 \\
\hline Prostat & 1 & 3 & Colon & - & 2 \\
\hline Skin & 1 & 1 & Prostat, $\mathrm{n}$ (count) & & \\
\hline Bladder & 1 & - & Colon & - & 6 \\
\hline Pancreas & - & 2 & Larynx & - & 2 \\
\hline Tongue & - & 1 & Lung & - & 1 \\
\hline Bladder, n (count) & & & Skin, $n$ (count) & & \\
\hline Lung & - & 6 & Lung & - & 5 \\
\hline Prostat & 2 & 2 & Breast & - & 1 \\
\hline Skin & 1 & - & Colon & - & 1 \\
\hline Larynx & - & 2 & Esophagus, $\mathrm{n}$ (count) & & \\
\hline Colon & - & 2 & Lung & - & 1 \\
\hline Ovary, n (count) & & & Thyroid, $\mathrm{n}$ (count) & & \\
\hline Breast & 2 & 1 & Kidney & - & 1 \\
\hline Endometrium & 1 & - & Testis, n (count) & & \\
\hline Colon & - & 2 & Lung & - & 1 \\
\hline Pancreas & - & 1 & Ureter & - & 1 \\
\hline
\end{tabular}

lon, 7 patients with colon-prostate, 6 patients with breast-ovary, 5 patients with lung-kidney, 5 pa- tients with skin-lung, and 4 patients with colonlung were detected (Table 2). 
TABLE 3. Univariate variables evaluation for survival analysis

\begin{tabular}{|c|c|c|c|c|c|}
\hline \multicolumn{2}{|l|}{ All } & \multicolumn{2}{|c|}{ Synchronous } & \multicolumn{2}{|c|}{ Metachronous } \\
\hline $\begin{array}{l}\text { Median survival } \\
\qquad(95 \% \mathrm{CI})\end{array}$ & $\mathrm{p}$ & $\begin{array}{l}\text { Median survival } \\
\qquad(95 \% \mathrm{CI})\end{array}$ & $\mathrm{p}$ & $\begin{array}{l}\text { Median survival } \\
\qquad(95 \% \mathrm{CI})\end{array}$ & $\mathrm{p}$ \\
\hline
\end{tabular}

\section{Age, year \\ $<60$ \\ $\geq 60$}

Gender

Male

Female

Smoking

Yes

No

Alcohol

Yes

No

Primarytumour site

Breast

Larynx

Colon

Lung

Esophagus

Primarytumour histology

Adenocancer

Squamouscell

Others*

Primarytumour stage

Localized

Metastatic

Primarytumour treatment

Non-curative

Curative
$22.1(12.5-31.8)$

$24.9(16.1-33.8)$

21.5 (14.9-28.2)

39.8 (22.9-56.7)

21.5 (14.7-28.3)

$33.4(17.9-48.9)$

$24.9(15.2-34.6)$

$22.1(15.6-28.6)$

86.2 (79.4-93.1)

$19.3(12.4-26.2)$

$22.1(8.8-35.4)$

$22.2(0.9-43.5)$

$3.9(2.8-5.8)$

$24.9(15.5-34.3)$
$22.2(11.8-32.50)$
$13.5(0.4-26.5)$

0.98

$8.9(0.1-21.5)$

$5.3(0.1-13.4)$

$29.6(18.7-40.5)$

15.7 (4.9-26.4)

13.7 (3.7-23.8)

30.7 (20.1-41.3)

0.64

$5.1(1.0-16.4)$

$8.9(4.2-13.6)$

0.17

7.9 (2.1-13.8)

0.42

$7.9(2.3-13.6)$

$6.1(3.8-8.4)$

$8.9(2.9-14.9)$

$5.3(3.3-7.2)$

0.005

5.1 (3.7-6.3)
0.45

$34.4(1.2-67.6)$

0.83

35.9 (27.4-44.5)

0.59

$34.2(26.1-42.2)$

0.56

$10.7(0.6-20.7)$

44.7 (23.7-65.7)

0.87

34.8 (20.9-48.7)

0.62

$10.7(0.1-24.1)$

35.9 (21.3-50.6)

0.93

48.9 (24.7-73.1)

0.23

34.4 (25.4-43.3)

0.05

0.96

$\mathbf{0 . 0 0 1} 12.1(7.7-16.4)$

0.01

16.1 (9.9-22.3)

0.001
86.2 (79.4-93.1)

$28.7(0.1-116.2)$

$22.1(7.3-37.1)$

$34.2(17.5-50.8)$

$20.7(0.1-23.1)$

$34.4(21.2-47.6)$

0.43

$34.8(29.4-40.3)$

$48.9(0.1-49.1)$

$41.1(25.1-57.1)$

0.09

$28.7(18.7-38.7)$

$26.4(19.4-33.4)$

0.36

0.03

$41.1(27.5-54.6)$
Ninety of 180 patients with double primary tumors died. The median survival was calculated as 23.7 months [95\% confidence interval (CI) 16.730.7]. When the median survival was compared according to gender, it was detected as 21.5 months (95\% CI 14.9-28.2) in males and 39.8 months (95\% CI 22.9-56.7) in females $(p=0.17)$. The median survival was calculated as 22.1 months in alcohol users (95\% CI 15.6-28.6) $(\mathrm{p}=0.45)$, whereas it was 24.9 months (95\% CI 15.2-34.6) in those who did not use alcohol. Also, it was 21.5 months (95\% CI 14.7-28.3) in smokers and 33.4 months (95\% CI 17.9-48.9) $(\mathrm{p}=0.42)$ in nonsmokers. The median survival in those whose primary tumor organ was breast, colon, larynx, pancreas, and esophagus was calculated as $86.2,22.2,22.1,19.3,6.6$, and 3.9 months, respectively. The survival rate of the patients with primary tumor histology as an adenocarcinoma and a squamous cell carcinoma was 24.9 months (95\% CI 15.5-34.3) and 22.3 months (95\% 
TABLE 4. Multivariable analysis of prognostic factors for survival in patients with multiple primary tumours

\begin{tabular}{lccc} 
& $\mathrm{RR}$ & $95 \% \mathrm{CI}$ & $\mathrm{p}$ \\
\hline Age, $\geq 60$ years & 0.561 & $0.226-1.392$ & 0.21 \\
Gender, male & 0.320 & $0.059-1.736$ & 0.19 \\
$\begin{array}{l}\text { Primarytumour site } \\
\quad \text { Colon }\end{array}$ & 2.451 & $0.649-9.258$ & 0.18 \\
$\quad$ Lung & 2.710 & $0.876-8.377$ & 0.08 \\
$\quad$ Larynx & 2.163 & $0.669-6.995$ & 0.19 \\
$\begin{array}{l}\text { Primarytumour stage } \\
\quad \text { Metastatic }\end{array}$ & 2.837 & $1.075-7.490$ & $\mathbf{0 . 0 3}$ \\
$\begin{array}{l}\text { Primarytumour treatment } \\
\quad \text { Non-curative }\end{array}$ & 0.850 & $0.236-3.064$ & 0.81 \\
$\begin{array}{c}\text { Multipleprimary status } \\
\quad \text { Synchronous }\end{array}$ & 4.582 & $2.085-10.070$ & $<\mathbf{0 . 0 0 1}$ \\
\hline
\end{tabular}

CI: Confidence interval; RR: Relative risk.

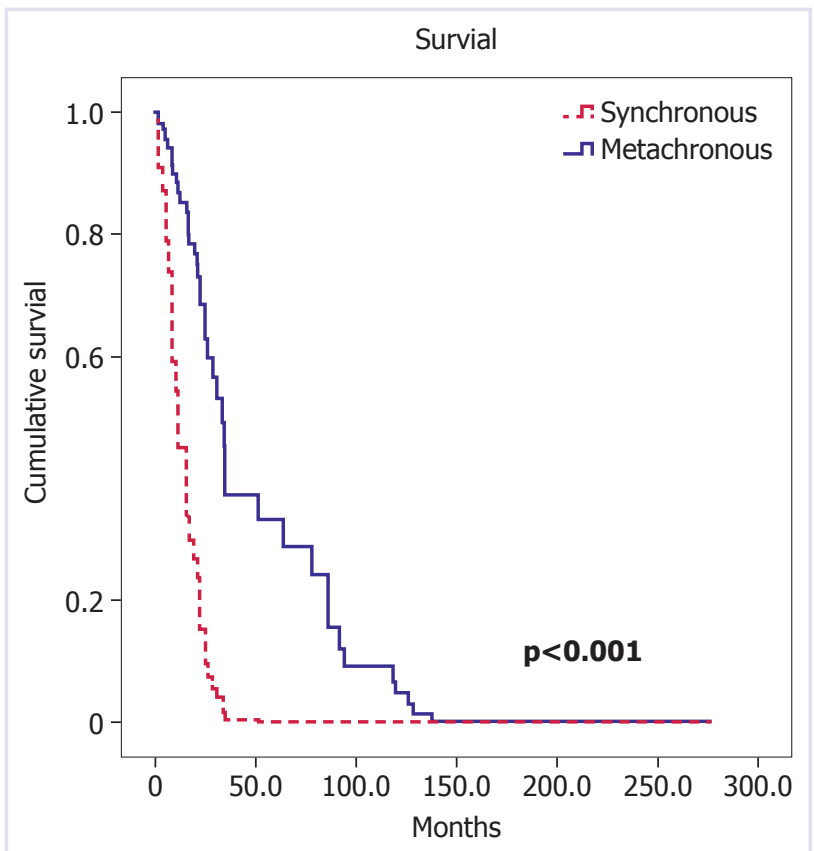

FIGURE 2. Survival rate of patients with synchronous and metachronous tumors.

CI $11.8-32.5)$, respectively $(p=0.06)$. The median survival rate in the patients with a primary organlimited and metastatic tumors was 29.7 months (95\% CI 18.7-40.5) and 15.7 months (95\% CI 4.9-26.4), respectively $(p=0.001)$. The rate was
30.7 months (95\% CI 20.1-41.3) and 13.7 months (95\% CI 3.7-23.8) in the patients who received a curative therapy and those who did not receive a curative therapy, respectively $(\mathrm{p}=0.005)$. The median survival of co-occurrenceof synchronous tumors and metachronous tumors was 8.9 months (95\% CI 3.4-14.5) and 35.9 months (95\% CI 27.6-44.3), respectively $(\mathrm{p}<0.001)$.

Univariate analyses showed that the primary site, stage, and status of receiving curative therapy of the tumor could be used to predict patient survival (Table 3). Multivariate analysis showed that the presence of a synchronous tumor and a primary tumorat the metastatic stage wasassociated with poor prognosis and shorter survival in patients with two primary tumors (Table 4 and Figure 2).

\section{DISCUSSION}

The prevalence of multiple primary tumors increases in relation to several factors such as increase in the number of treatment options, the fact that the progression of some cancer cells becomes similar with some chronic disease patterns, and increase in the use of cytotoxic agents and ionized radiation [5-7]. The number of patients with secondary tumorsmay also increase with the increase in the number of cancer patients in the following years. Therefore, extreme caution is required regarding the development of secondary tumors in the patients who are followed up and treated for primary tumors. Both having an accompanying synchronous tumor and the presence of a primary tumor at the metastatic stage were associated with bad prognosis in terms of survival in the present study.

Studies on multiple primary tumors available in the literature are generally retrospective studies. They are especially based on the Warren and Gates criterion and conducted by classifying patients as synchronous and metachronous [8]. The prevalence of multiple primary tumors was reported as $0.73 \%$ in the study by Haddow et al. [9] conducted with 58,333 cancer patients in 1972, $3.97 \%$ in the study by Storm et al. [10] conducted with 379,941 cancer patients in 1985 , and $1.03 \%$ in the study by Aydiner et al. [11] conducted with 
26,000 cancer patients in 2000 . This rate was $1.9 \%$ in the present study. This variation might be due to different strategies used in defining etiological causes and diagnoses of tumors.

Smoking seems to be an important risk factor for the development of multiple primary tumors [12]. The statistically significant rate of smoking in the synchronous and metachronous groups was $47 \%$ and 34\%, respectively, in the study by Aydiner et al. [11]. The rate of cigarette smokers in the synchronous and metachronous groups was $67 \%$ and $51 \%$, respectively, in the present study. Hence, it can be concluded that smoking is an important risk factor for the development of synchronous tumors. Especially, a strong correlation exists between squamous cell carcinomas and cigarette smoking. The rate of smoking was found to be significantly high in tumors known to be related to smoking, such as lung, larynx, kidney, bladder, and pancreas. The patients who had a smoking history lived about 12 months less compared with nonsmokers, although the survival rate was not statistically significant.

Alcohol use is a well-defined factor in the etiology of cancers such as liver, esophagus, breast, and colorectal [13]. The patient data about alcohol use could not be accessed due to registry failure in many studies about the development of multiple tumors., Alcohol use did not make a meaningful difference in terms of survival in the present study. However, since the amount of alcohol usedcould not be assessed clearly, this issue wasc onsidered as a weak point in data evaluation.

When the data was analyzed for co-occurrence, head and neck-lung and colon-lung were the most relevant co-occurrences among synchronous tumors. The most frequent co-occurrences in the study by Feng Li et al. conducted with 175 lung cancer patients with double primary tumors, were lung-colon, lung-bladder, lung-breast, and lungesophagus [14]. Therefore, if the same tumor is detected in these organs, the possibility of having a second primary tumor should be considered before the diagnosis of metastasis.

Breast-endometrium co-occurrence may be the result of hormone therapy for breast cancer, due to the increased risk of endometrial cancer. Since the mutation analysis was not conducted, the assessment might not be accurate. Gene mutation screening might be useful in patients detected with tumor co-occurrence in the future.

When all these data were analyzed, it was foundthat metachronous tumors were more likely to have higher survival rates, such as breast, prostate, and colon. The association between smoking and alcohol use was weaker in metachronous tumors than in synchronous tumors. As a result, the survival rate was significantly higher in metachronous tumors in the present study.

Limited data are available in the literature on the progression and treatment of multiple primary tumors. In the study by Irimie et al. conducted with 62 cases with double primary tumors, it was found that curative surgery was applied to $40 \%$ of the first primary synchronous tumors, whereas it could only be applied to $30 \%$ of the secondary tumors [15]. In the same study, it was found that only $10 \%$ of metachronous tumors could undergo curative surgery. Further, $57 \%$ of the first primary synchronous tumors were detected at the organ-limited stage and curative treatments were applied to the all of them. However, the rate of treatment application to the first primary metachronous tumors was $80 \%$. This result explained the difference between the survival rates of synchronous and metachronous tumors. The survival rate of patients with organ-limited primary tumor, who could undergo curative surgery, was significantly longer.

The present study had some limitations such as a retrospective design, lack of gene mutation analyses, and homogeneity of the patient population. If quantitative data could have been presented (as number of pack-years of smoking) its prognostic effect would have been more accurately evaluated.

In conclusion, the present study showed that synchronous and metastatic statuses of the disease are independent risk factors for mortality. In the light of this information, a secondary cancer followup may be informative, especially in the patients with malignancy. 
Conflict of Interest: None declared.

Financial Disclosure: The authors declared that this study has received no financial support.

Authorship contributions: Concept - A.G.; Design - O.K.; Supervision - I.C., S.U.; Material - I.C., O.K.; Data collection or processing - A.G., H.K., B.E., E.T., M.B.H., I.H., O.K.; Analysis - B.E., O.K.; Literature search - A.G.; Writing - A.G.; O.K.; Critical review - I.C., S.U., B.E.

\section{REFERENCES}

1. Tachimori Y. Cancer screening in patients with cancer. Jpn J Clin Oncol 2002;32:118-9.

2. Demandante CG, Troyer DA, Miles TP. Multiple primary malignant neoplasms: case report and a comprehensive review of the literature. Am J Clin Oncol 2003;26:79-83.

3. Suzuki T, Takahashi H, Yao K, Inagi K, Nakayama M, Makoshi $\mathrm{T}$, et al. Multiple primary malignancies in the head and neck: a clinical review of 121 patients. Acta Otolaryngol Suppl 2002;88-92.

4. Ng AK, Kenney LB, Gilbert ES, Travis LB. Secondary malignancies across the age spectrum. Semin Radiat Oncol 2010;20:67-78.

5. Hemminki K, Boffetta P. Multiple primary cancers as clues to environmental and heritable causes of cancer and mechanisms of carcinogenesis. IARC Sci Publ 2004;289-97.

6. Carey TE. Field cancerization: are multiple primary cancers monoclonal or polyclonal? Ann Med 1996;28:183-8.

7. Wynder EL, Mushinski MH, Spivak JC. Tobacco and alcohol consumption in relation to the development of multiple primary cancers. Cancer 1977;40:1872-8.

8. Warren S, Gates O. Multiple primary malignant tumors: a survey of the literature and statistical study. Am J Cancer 1932;16:1358-414.

9. Haddow AJ, Boyd JF, Graham AC. Multiple primary neoplasms in the Western Hospital Region, Scotland: a survey based on cancer registration data. Scott Med J 1972;17:143-52.

10. Storm HH, Jensen OM, Ewertz M, Lynge E, Olsen JH, Schou G, et al. Summary: multiple primary cancers in Denmark, 1943 80. Natl Cancer Inst Monogr 1985;68:411-30.

11. Aydiner A, Karadeniz A, Uygun K, Tas S, Tas F, Disci R, et al. Multiple primary neoplasms at a single institution: differences between synchronous and metachronous neoplasms. Am J Clin Oncol 2000;23:364-70.

12. Leon ME, Peruga A, McNeill A, Kralikova E, Guha N, Minozzi $S$, et al. European Code against Cancer, $4^{\text {th }}$ Edition: Tobacco and cancer. Cancer Epidemiol 2015;39 Suppl 1:S20-33.

13. Williams LA, Olshan AF, Tse CK, Bell ME, Troester MA. Alcohol intake and invasive breast cancer risk by molecular subtype and race in the Carolina Breast Cancer Study. Cancer Causes Control 2016;27:259-69.

14. Li F, Zhong WZ, Niu FY, Zhao N, Yang JJ, Yan HH, et al. Multiple primary malignancies involving lung cancer. BMC Cancer 2015;15:696.

15. Irimie A, Achimas-Cadariu P, Burz C, Puscas E. Multiple primary malignancies--epidemiological analysis at a single tertiary institution. J Gastrointestin Liver Dis 2010;19:69-73. 